\title{
Long-Term Outcome Call into Question the Benefit of Positive Fluid Balance and Colloid Treatment After Aneurysmal Subarachnoid Hemorrhage
}

\author{
Andrea Orfanakis · Ansgar M. Brambrink
}

Published online: 11 September 2013

(c) Springer Science+Business Media New York 2013

\begin{abstract}
Aneurysmal subarachnoid hemorrhage (SAH) has a high mortality and morbidity, and long-term outcome is determined by the functional capacity of the patient. Preventing delayed cerebral ischemia that will result in delayed ischemic neurological deficits (DINDs) is a paramount treatment goal during the post-hemorrhage period. There is still controversy regarding the best strategies. While therapeutic induction of hypertension, hypervolemia, and hemodilution ("Triple-H therapy") is the most commonly accepted treatment, uncertainty remains, among others, whether colloids versus crystalloids should be utilized, and whether maintaining a positive fluid balance in patients with evidence for vasospasm improves long-term functional outcome.

Ibrahim and Macdonald [1] approached the problem by conducting a post-hoc analysis of an existing large database ( $n=413$; CONSCIOUS-1 trial [2]). First, they used propensity-score matching to determine whether the administration of colloids between days 3 and 14 (period of the highest risk for cerebral vasospasm/DIND after SAH) influences the incidence of DIND and of delayed infarction, and whether it influences the functional outcome 6-12 weeks after SAH (Glasgow outcome scale, modified Rankin scale [mRs], and NIH stroke scale [NIHSS]). Next, using a multivariate logistic regression model, they evaluated any association that an overall fluid balance during the DIND risk period (3-14 days) has on the same outcome
\end{abstract}

This article is an editorial to $10.1007 / \mathrm{S} 12028-013-9860-\mathrm{Z}$.

A. Orfanakis · A. M. Brambrink $(\bowtie)$

Department of Anesthesiology and Perioperative Medicine,

Oregon Health \& Science University, UHN-2, 3181 SW Sam

Jackson Park Road, Portland, OR 97239-3098, USA

e-mail: brambrin@ohsu.edu parameters. They found that treatment with colloids during the DIND risk period does not reduce the risk for DIND or delayed cerebral infarcts, but that it rather was associated with worse functional outcomes (NIHSS). Equally important, they found that a positive fluid balance during the DIND risk period was associated with prolonged length of stay in the ICU and worse functional outcome (mRS) at 12 months after SAH. However, they also found that patients with angiographic evidence of severe vasospasm had more delayed cerebral infarcts when their fluid balance remained negative during the DIND risk period. The authors conclude that the volume status of patients after SAH should be managed carefully and colloids should be restricted to selected patients and administered only under careful monitoring.

Their findings are clinically important despite the limitations of post-hoc analysis. The study has relevance for several reasons:

First, over the last several years in the medical literature, studies have surfaced regarding the negative effects of IV fluid over-resuscitation. This includes both positive fluid balance per day over an extended period of time during the hospitalization, as well as high "throughput" of IV fluids in the setting of an even fluid balance. It is now well documented that both management strategies are harmful in patients with sepsis, ARDS, after trauma or during the perioperative period [3-9]. However, the exact mechanism remains unclear. The new results presented by Ibrahim and Macdonald [1] suggest that equally, the injured brain may not be immune to the negative effects of fluid overadministration. Their results are particularly important, as it has been considered a gold standard of therapy to induce and maintain positive IV fluid balance in patients after SAH during the window of vasospasm, in order to prevent DIND. Interestingly enough the data suggest that even in 
the context of clinical signs of DIND, hemodilution/ hypervolemia, i.e., a positive fluid balance, even as a rescue therapy, does not protect against neuronal damage, but rather is detrimental in the immediate hospital period as well as to the long-term functional outcome.

Second, Ibrahim and Macdonald [1] found that treatment with colloids during the DIND risk period was not neuroprotective, but, in fact negatively influenced the longterm functional outcome of patients after SAH. Also, they found that treating with colloids did not change the net fluid balance compared to a straight crystalloid treatment regime. It would have been very interesting to understand whether this is true for all types of colloids. Plasma, hetastarch, and albumin are very different substances with unique effects on multiple organ systems. The authors decided to group the outcomes following the use of all three of these substances, which precludes such discussion based on their dataset. The literature on the negative effects of plasma administration for other organ systems than the brain is prominent today [10], and further research will be necessary to address this clinical question and to understand whether SAH patients can safely receive any colloid during their treatment period in the ICU.

Third, the traditional thinking is to avoid a negative fluid balance in SAH at all costs, which invariably leads to high IV fluid "throughput." The data presented by Ibrahim and Macdonald [1] support such practice when patients have angiographic evidence of severe cerebral vasospasm. Under those condition patients are at a higher risk for delayed cerebral infarcts and a negative fluid balance increases that risk according to their data. However, this is a small subgroup of patients after SAH. Many patients do not have angiographic evidence of severe cerebral vasospasm, and Ibrahim and Macdonald's data suggest that for these patients inducing and maintaining hypervolemia during the first 2 weeks of their hospitalization does not protect against unfavorable outcomes like delayed neurologic deficit or delayed cerebral infarction but is rather harmful. Moreover, fluid treatment that aims for hypervolemia in this patient population is usually heavily based on isotonic or hypertonic salt solutions. This practice results in a higher incidence of hyperchloremic metabolic acidosis, a pathophysiologic state, which is also gaining interest in its ability to do harm to various tissue groups of the body $[6,11]$.

Fourth, the commonly held belief in therapeutic use of triple $\mathrm{H}$ therapy has come under question in the recent years. Two RCTs have touched on the risks of hypervolemia in SAH. However, both trials were underpowered but their results were nevertheless thought-provoking [12]. It is a positive development when fixed belief systems and "commonly held" practices undergo re-evaluation by the scientific community on a routine basis. It was, therefore, timely that Ibrahim and Macdonald set out to determine if triple- $\mathrm{H}$ therapy is beneficial to all aneurysmal $\mathrm{SAH}$ patients during the DIND risk period. The next step, though, would be to further investigate the pathophysiology of DIND in the light of the new findings and concerns. It remains, for example, unknown whether there is a direct causal relationship between cerebral vasospasm and delayed neuronal deficit or delayed neuronal infarction. Large vessel and small vessel spasm may not result from the same mechanism nor do they likely have the same mechanism to cause functional deficit or morphologic brain injury. Among others, putative processes such as cortical spreading ischemia and activation of specific inflammatory pathways are currently topics for intense research [13, 14]. Contributions from the laboratory will likely guide new therapeutic approaches in this field.

Finally, before the complex pathophysiology of delayed neurologic injury can be better understood, Ibrahim and Macdonald [1], based on their findings, are supporting clinicians in a judicious IV fluid management strategy of SAH patients during high-risk period for DIND. Moreover, not all patients after aneurysmal SAH are at equal risk for delayed neuronal injury. Therefore, not all patients need to be managed equally, and the presented data will also support clinicians when tailoring therapies to select patients rather than treating all patients the same, who present with this potentially devastating disease.

\section{References}

1. Ibrahim GM, Macdonald RL. The effects of fluid balance and colloid administration on outcomes in patients with aneurysmal subarachnoid hemorrhage: A propensity score-matched analysis. Neurocrit Care. 2013. doi:10.1007/s12028-013-9860-z.

2. Macdonald RL, Kassell NF, Mayer S, Ruefenacht D, Schmiedek $\mathrm{P}$, Weidauer $\mathrm{S}$, et al. Clazosentan to overcome neurological ischemia and infarction occurring after subarachnoid hemorrhage (CONSCIOUS-1): randomized, double-blind, placebo-controlled phase 2 dose-finding trial. Stroke. 2008;39:3015-21.

3. Adesanya A, Rosero E, Timaran C, Clagett P, Johnston WE. Intraoperative fluid restriction predicts improved outcomes in major vascular surgery. Vasc Endovasc Surg. 2008;42(6):531-6.

4. Marjanovic G, Villain C, Juettner E, zur Hausen A, Hoeppner J, Hopt UT, Drognitz O, Obermaier R. Impact of different crystalloid volume regimes on intestinal anastomotic stability. Ann Surg. 2009;249(2):181-5.

5. De Aguilar-Nascimento JE, Diniz BN, do Carmo AV, Silveira EA, Silva RM. Clinical benefits after the implementation of a protocol of restricted perioperative intravenous crystalloid fluids in major abdominal operations. World J Surg. 2009;33(5): 925-30.

6. Bundgaard-Nielsen M, Secher NH, Kehlet H. 'Liberal' vs. 'restrictive' perioperative fluid therapy-a critical assessment of the evidence. Acta Anaesthesiol Scand. 2009;53(7):843-51.

7. Groeneveld AB. Fluids in septic shock: too much of a good thing? Crit Care. 2010;14(1):101. doi:10.1186/cc8201.

8. Duke MD, Guidry C, Guice J, Stuke L, Marr AB, Hunt JP, Meade $\mathrm{P}, \mathrm{McSwain}$ NE Jr, Duchesne JC. Restrictive fluid resuscitation in 
combination with damage control resuscitation: time for adaptation. J Trauma Acute Care Surg. 2012;73(3):674-8.

9. Kulemann B, Timme S, Seifert G, Holzner PA, Glatz T, Sick O, Chikhladze S, Bronsert P, Hoeppner J, Werner M, Hopt UT, Marjanovic G. Intraoperative crystalloid overload leads to substantial inflammatory infiltration of intestinal anastomoses-a histomorphological analysis. Surgery. 2013;154(3):596-603.

10. Perel P, Roberts I, Ker K. Colloids versus crystalloids for fluid resuscitation in critically ill patients. Cochrane Database Syst Rev. 2013;2:CD000567.

11. McCluskey SA, Karkouti K, Wijeysundera D, Minkovich L, Tait G, Beattie WS. Hyperchloremia after noncardiac surgery is independently associated with increased morbidity and mortality: a propensity-matched cohort study. Anesth Analg. 2013;117(2): 412-21.

12 Rinkel GJ, Feigin VL, Algra A, van Gijn J. Circulatory volume expansion therapy for aneurysmal subarachnoid haemorrhage. Cochrane Database Syst Rev. 2004;4:CD000483.

13. Dumont AS, Dumont RJ, Chow MM, et al. Cerebral vasospasm after subarachnoid hemorrhage: putative role of inflammation. Neurosurgery. 2003;53(1):123-33.

14. Dreier JP, Major S, Pannek HW, Woitzik J, Scheel M, Wiesenthal D, Martus P, Winkler MK, Hartings JA, Fabricius M, Speckmann EJ, Gorji A, COSBID Study Group. Spreading convulsions, spreading depolarization and epileptogenesis in human cerebral cortex. Brain. 2012;135:259-75. 